\title{
Dissecting the pathways of tumour escape: "a question of life and death?"
}

\section{Dissecando os caminhos de escape do tumor: "uma questão de vida e morte?"}

\author{
Georgi Tchernev $^{1}$
}

Pietro Nenoff ${ }^{2}$

\begin{abstract}
Apoptotic pathways are providing important saveguard mechanisms in protection from cancer by eliminating altered and often harmful cells.

The disturbances of cell proliferation, differentiation and apoptosis are also found on specific signal-transduction pathways within the tumour cells and between these and the immune system. The article focuses attention on the evolution of the melanocytic naevi in the direction of a dysplastic or tumour cell. The determination of single molecules as prognostic parameters within cancer genesis seems to be problematic. New hopes are being placed on the treatment with TW-37, ABT-737 and TAT-Bim, which, to an extent, are able to support the programmed cell death. The clinical importance of these innovative therapies remains to be seen and should therefore, be viewed with considerable criticism.

Keywords: Apoptosis; bcl-2-Associated X Protein; Cell cycle; HLA antigens
\end{abstract}

Resumo: Caminhos apoptóticos estão fornecendo importantes mecanismos de salvaguarda na proteção contra o câncer através da eliminação de células alteradas e freqüentemente nocivas.

Os distúrbios de proliferação, diferenciação e apoptose celular são também encontrados nos caminhos específicos sinal-transdução dentro das células tumor e entre essas células e o sistema imunitário.

O artigo foca na evolução da verruga conhecida como melanocytic naevi em direção a uma célula displasica ou célula tumor. A determinação de moléculas isoladas como parâmetros de prognóstico dentro da gênesis do câncer parece problemática. Novas esperanças estão sendo colocadas no tratamento com TW37, ABT-737 e TAT-Bim, os quais, até certo ponto, são aptos a apoiar a morte celular programada (PCD). A importância clínica dessas terapias inovadoras permanece ainda a ser vista e devem, por essa razão, serem olhadas com considerável juízo crítico.

Palavras-chave: Apoptose; Antígenos HLA; Ciclo celular; Proteína X associada a bel-2

\section{INTRODUCTION}

The mechanisms of tumour escape have been the subject matter of active debates during the last several years although to this date they have found no definitive solution. ${ }^{1}$ They vary in the different tumours and often demonstrate differences within one and the same tumour but in different patients. It is very probable that this is where one must search to find the reason for the inefficiency of chemo- and immune therapy usually applied by the clinician.

It is still unclear whether the general tumour escape may be divided into two levels or subgroups, namely local (in the tissue) and peripheral (or exogenic, indirect, external). ${ }^{1}$ The last may be realized via various mechanisms.
Quite often tumour escape turns out to be a complex and probably strictly programmed process which runs following a certain sequence. This sequence, however, is far from being a constant value. And it is exactly this feature which leads to serious difficulties when the clinical dermatologists have to make their decisions. The differences in the behaviour of tumour cells probably depend on factors which haven't been thoroughly investigated.

The local and exogenic (or external) form of "tumour escape" quite often turn out to be "partners" acting according to a "plan" the major goal of which is the neutralization of the immune system and the rapid proliferation and metastatic development of the tumour cells.

\footnotetext{
Aprovado pelo Conselho Editorial e aceito para publicação em 15.12.2009.

* A study was carried out in the Department of Dermatology, Venereology and Dermatologic Surgery Kirchheim, Baden Württemberg in cooperation with The Laboratory for Medical Microbiology Partnership Dr Jürgen Herrmann, Prof Dr Pietro Nenoff \& Dr Constanze Krüger - Mölbis, Germany.

Conflict of interest: None / Conflito de interesse: Nenhum

Financial funding: None / Suporte financeiro: Nenhum
}

M.D. P.h.D. Spezialist in Dermatology and Venereology Department of Dermatology, Venereology and Dermatologic Surgery - Kirchheim, Germany Laboratory for Medical Microbiology Partnership Dr Jürgen Herrmann, Prof. Dr Pietro Nenoff \& Dr Constanze Krüger - Mölbis, Germany. 
Quite often decreased apoptosis in the tissue (non-immunologic type of tumour escape, endogenous form) could be accompanied by increased apoptosis of lymphocytes in the peripheral blood or by down regulation of certain HLA-I molecules (immunologic or exogenous form of tumour escape) ${ }^{1,2}$

The article focuses attention on tumours as a whole although it is also partially based on the evolution of the melanocytic naevi (concretely) in the direction of a dysplastic and/or tumour cell.

In addition, the behaviour of tumour cells in other kinds of tumours is also discussed, the effect of tumour cells on the immune system as well as the neutralization of the last within the framework of cancer genesis.

\section{Immunity in Cancer - Opinions and Hypothesis}

The two basic units which turn out to be problematic when defining the prognosis of patients with malignant tumours are: dysregulation of the cell cycle and the apoptosis in the tumour tissue on the one hand and the immunological response on the other. The different tumours possess a different "repertoire" of mechanisms, thanks to which they manage to "sneak out" from the impact of the immune system.

Tumour formations are capable to bring about the total destruction of the human organism by using various different mechanisms: 1 ) directly - via an invasive local growth and metastasis formation: local and/or distant, 2) via the initiation of antigene mimicry like the simulation of various dermatological diseases, like bullous or lichenoid dermatosis, for example. ${ }^{1,3}$ The paraneoplastic induced cutaneous diseases (whether having bullous or lichenoid feature) are often therapeutically resistant to standard therapeutic approaches. In order to improve the clinical status of the patients in such difficult cases, quite often pulse and impact therapies with corticosteroids are applied as well as immune suppressing agents which additionally suppress the T- and B-cellular immunity. ${ }^{3}$ In this way the immune system is inactivated and the further formation of metastasis is supported.

The result is a so-called "vicious circle", which is very difficult to stop, if at all. The paraneoplastic diseases of the skin are one of the reasons for frequent disputes among clinicians regarding the necessity of certain diagnostic algorhythms. On the one hand it are just these algorhythms which guarantee the considerable assureness for the patients while on the other hand, they guarantee the lasting success or the lack of relapse after the running of a given therapy. ${ }^{4}$ It is sad but the staging of such esplorative programs is not a standard method or practice applicable in every European Dermatologic Clinic.
A number of classic dermatoses (like the bullous and lichenoid dermatosis for example) quite often appear to be a side effect, an associatied phenomenon, an "incorporated phenomenon" or an alarmgenerating sign for damages in the tissue homeostasis. ${ }^{3,4}$ Are these violations indirectly caused by the tumour tissue? These disturbances allow the tumour to survive, and the T- and B- cell immunity will be inactivated with the result that metastasis are created and proliferate, freely?

It is interesting to note that the antigen mimicry is manifested not in all patients but only in some. It appears as if when finding it impossible to cope with the immune system, than, the tumour starts to simulate diseases which make the physician suppress the Tand B- cellular immunity with different therapeutical approaches. It is not exactly known when the tumour "decides to solve the T cell immunity -problem" and when does it indirectly force the team of clinicians to support it by immitating a classical dermatological autoimmune disease?

According to other authors, even the tumour itself is able to counterattack the tumour-infiltrating lymphocytes and to eliminate them. ${ }^{5,6}$ Although several in vitro research results show the efficiency of congenital and acquired immunity in the elimination of tumour cells; in vivo, these tumours remain untouched in many of the cases, by systems effectors of the immune system. Maybe the reasons for this phenomenon (in some cancer forms like breast cancer and infiltrating ductal carcinoma) may be found in the failure of immune system to overcome the quickly proliferating tumour cells, in the production of certain humoral factors derived from the tumour, and also in the dysfunction of the ?-cells, which may have a different genesis. ${ }^{78}$

The presence of killer lg receptors (KIR) on the T-lymphocytes themselves and their indirect blocking by tumours, as well as the inherent property of the tumours to escape from the programmed cell death by autocrinouse secretion of Fas $\mathrm{L}$ for instance, is also at the root (probably) of the so called exogenous tumour escape. ${ }^{1,9}$

The presence of a normal immunity (innate or acquired), purposed to eliminate tumour antigens, and also the presence of auto-immunity (conditioned by the antigen mimicry also), clearly illustrates how complicated is the problem which the clinical oncologist has to face. The way in which immunity and autoimmunity chains are developed includes different components not only at the initial, but also at the effectorial stage. The organism uses a part of these mechanisms to try to resist the tumour escape and quite frequently the result is favourable for the tumour itself. 


\section{Cell Cycle Regulation and Tumour Escape}

Apoptosis is an active and physiological process indispensable for normal tissue homeostasis, which could act as a counterbalance for cell proliferation. At the same time apoptosis provides fundamental safeguard mechanisms in protection from cancer by eliminating altered and potentially harmfull cells. Apoptotic pathways could be devided in extrinsic and intrinsic apoptotic pathways (Figure 1). The mitochondrial pathway belongs to the intrinsic apoptotic pathways.

Complex signal transduction systems, or the socalled checkpoints, could regulate growth arrest, DNA-repair and apoptosis and thereby prevent the formation of tumour cells (Figure 2). ${ }^{10}$

The genome instability in tumour tissue is due to the dysregulation of the so-called "checkpoints" of the cell cycle. ${ }^{11}$ The representatives of Cip, Kip and INK4-tumour suppressing families are the effectorial molecules within these checkpoints. The main representatives of these families are: $\mathrm{p} 21^{\text {Cip }}, \mathrm{p} 27^{\text {Kip }}, \mathrm{p} 57^{\text {Kip }}$ $\mathrm{p} 16^{\mathrm{INK} 4 \mathrm{a}}, \mathrm{p} 15^{\mathrm{INK} 4 \mathrm{~b}}, \mathrm{p} 18^{\mathrm{INK}\{\mathrm{c}}$ and $\mathrm{p} 19^{\mathrm{INK}\{\mathrm{Ad}} \cdot{ }^{10,11}$

As an important transcription factor, $\mathrm{p} 53$ drives the expressions of different proteins, including the cell cycle regulators $\mathrm{p} 21$, which results in the blocking of the cell devision, thus providing time for DNA repair (Figure 2). In other cases p53 triggers transcription of proapoptotic proteins such as Bax, Noxa, Puma, Bik/Nbk and Bid. Furthermore, cytosolic p53 may also directly interact with some important Bcl-2 family members to trigger mitochondrial apoptosis. ${ }^{12,13,14}$

$\mathrm{Rb}$ is an inhibitor of cell proliferation. CDKs are essential components of the cell-cycle engine. $\mathrm{Rb}$ has two important tasks: it induces blockage of the cell cycle and keeps the apoptosis at bay. In this process, the blockage of proliferation is caused by $\mathrm{Rb}$ through

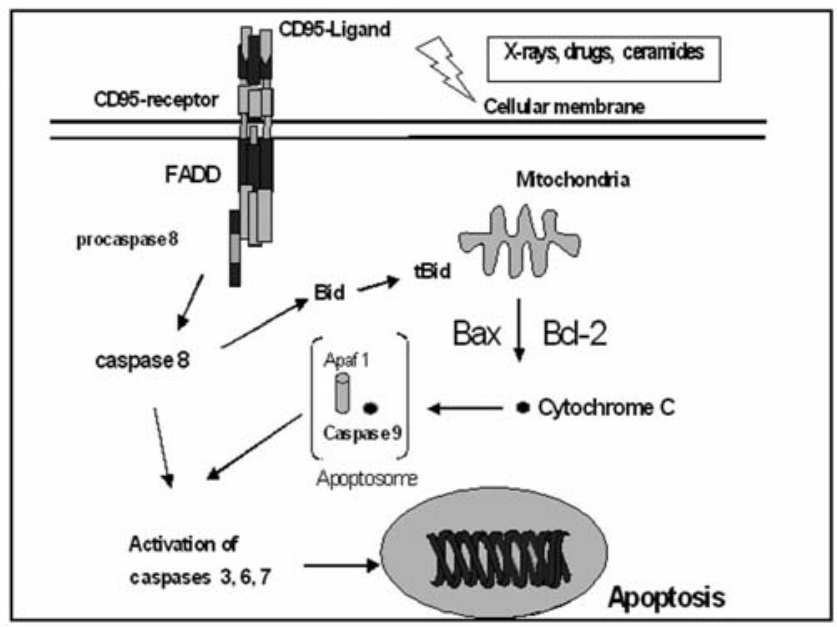

Figure 1: p53 and its role in the regulation of the "Cell-Cycle Engine". The regulation of the CDK activities in different phases of the cell cycle controls the correct process of DNA synthesis and replication

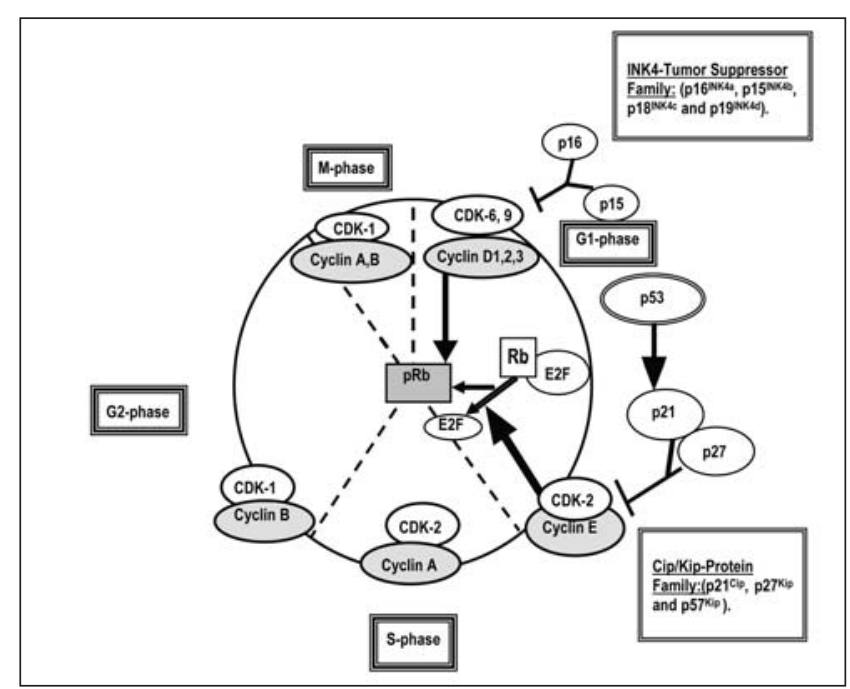

Figure 2: Pathways for induction of apoptosis: direct through activation of the $\mathrm{CD} 95$ receptor by means of $\mathrm{CD} 95$ ligands; and indirect through damaging cell membrane induced by drugs, X-rays, ceramides. Of crucial importance is the expression of pro- and antiapoptotic proteins like Bax and Bcl-2 having impact on the permeability of the mitochondrial membrane

repression of cyclin E, cyclin A and Cdc-2 genes (Figure 2). ${ }^{10,15}$ The promoters of these proteins possess specific E2F binding sites. By repressing the expression of these genes, $\mathrm{Rb}$ can block the cell proliferation. $\mathrm{Rb}$ is an important downstream effector in the $\mathrm{p} 53 / \mathrm{p} 21 \mathrm{Cip} 1$ pathway, and $\mathrm{Rb}$ can arrest damaged cells in the G1-, S- or G2-phases of the cell cycle (Figure 2) ${ }^{10,11}$ The activation of $\mathrm{p} 53 / \mathrm{p} 21$ leads to inhibition of the cell cycle, and the tumour suppressor protein $\mathrm{Rb}$ rests in its hypophosphorylated or active form that binds E2F (pRb = hyperphosphorylated, inactive form; $\mathrm{Rb}=$ hypophosphorylated, active form) (Figure 2). The tumour suppressor protein in retinoblastoma $(\mathrm{Rb})$ is one of the important proteins that can cause blockage of the cell cycle. $\mathrm{Rb}$ is capable of inhibiting the transcription factor E2F and c-Abl tyrosine kinase. Thus, $\mathrm{Rb}$ attacks through indirect inhibition of E2F in the cell cycle (Figure 2). ${ }^{10,15}$

The presence of defects affecting the regulators of these "transition points" makes the removal of certain anomalies, which are still affecting the cells that are "subject to malignant transformation", impossible (Figure 2).

This probably underlies the generation of immunoresistant tumour formations, which initially escape from the internal cell-controlling mechanisms. ${ }^{1,10}$

The exact mechanisms according to which the control on cell proliferation and programmed cell death are avoided are not completely clarified. ${ }^{1,11}$

Although the presence of micro-satellite instability plays an important role for the development of 
some tumours, the finding of mutations of the proapoptotic proteins and the regulators of the cell cycle are not always the leaders of their evolution.

Frequently, these modifications arise at later stages, during the so-called "advanced stage" ${ }^{16}$

This is the way in which the genetic instability, the impossibility to induce the programmed cell death and the tumour escape are mutually empowered..$^{1,10,11}$

\section{Bcl-2 family and Tumour Escape}

Bcl-2 proteins are the most important regulators of the mitochondrial apoptotic pathway. More than 20 known proteins of this family are already known (incl. alternative splice products). These proteins can be separated according to their activity in pro and anti-apoptotic (Figure 1).

Several anti-apoptotic proteins of the mitochondrial membrane protect the membrane's integrity. They bind to proapoptotic multidomain proteins Bax and Bak and thus block their activity. Proteins like Bcl-2 and Bcl-XL could prevent Bax translocation and activation. ${ }^{17-19} \mathrm{Bcl}-\mathrm{XL}$ and $\mathrm{Mcl}-1$ have been also shown to sequester Bak in mitochondria. ${ }^{20}$

The misbalance in the expression of the pro and anti-apoptotic representatives of Bcl-2 protein family in the mitochondria apoptosome is capable of giving advantage to tumour cells and indirect supports the tumour escape. ${ }^{1,11}$

The reasons for making the activation of the programmed cell death impossible are different. Death receptors, playing a key role in the activation of the exogenous or external apoptotic tract, may be affected (activated/blocked). ${ }^{1,21,22}$ The location of these receptors may be either in the tumour cells themselves, or in the peripheral lymphocytes as well (Figure 1) ${ }^{23,24}$ Precisely this link shows the unbreakable connection between the exogenic and endogenic forms of the tumour escape, as well as between the processes of uncontrolled cell proliferation, apoptosis, malignant transformation and immune system. ${ }^{2}$

It is considered that certain genetic alterations affecting the expression of the pro- and antiapoptotic genes and molecules (Bax, Bak and Bcl-2), as well as the modulators of the cell cycle (p21, p27, p53 and $\mathrm{Rb})$, underlie the tumour progress. ${ }^{2}$ The qualitative and quantitative assessment of the already mentioned proteins in the primary tumour tissue (in certain patient groups) would probably be able to provide an important information about the risk of a possible tumour progression and the patient's capacity to survive (Figures 3,4,5,6). ${ }^{2}$

Apoptosis is executed and regulated by several groups of proteins. Bcl-2 family proteins are the main regulators of the apoptotic pathways acting either to inhibit or promote it. More than 20 members of the

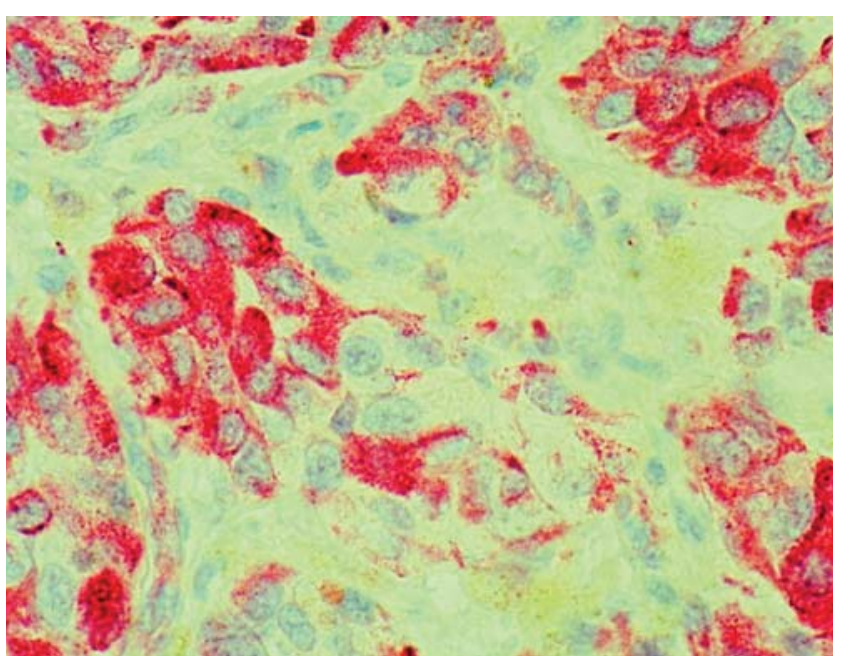

FIGURE 3: Expression of Bax in tumour tissue from patient with cutaneous melanoma (own results, Anti-Bax clone YTH-2D2, dilution 1:200, Trevigen, Maryland USA)

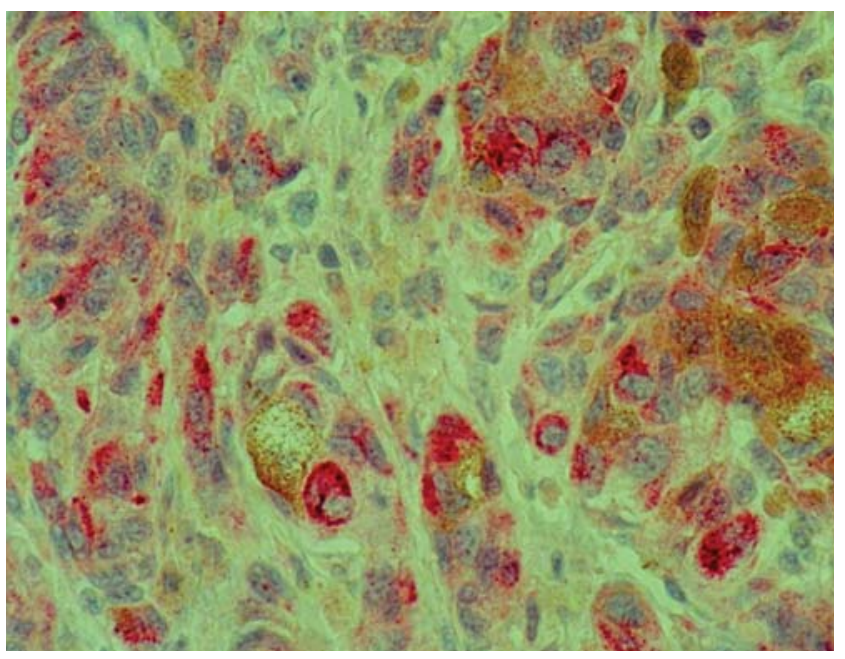

FIGURE 4: Expression of Bak in tumour tissue from patient with cutaneous melanoma (own Results, Anti-human Bak, clone A3538, dilution 1:100, DAKO)

family have been identified so far and most have two or more isoforms. Alternative splicing is one of the major mechanisms providing proteomic complexity and functional diversification of the pro and antiapoptotic Bcl-2 family proteins.

Pro- and anti-apoptotic Bcl-2 family members should function in harmony for the regulation of the apoptosis and cell cycle regulation in the normal tissue. Any mechanism breaking down this harmony could contribute to many diseases, including cancer. Recent studies have shown that manipulation of the alternative splicing mechanisms could provide an opportunity to restore the proper balance of these regulator proteins of splicing mechanisms as a potential therapeutic approach. 


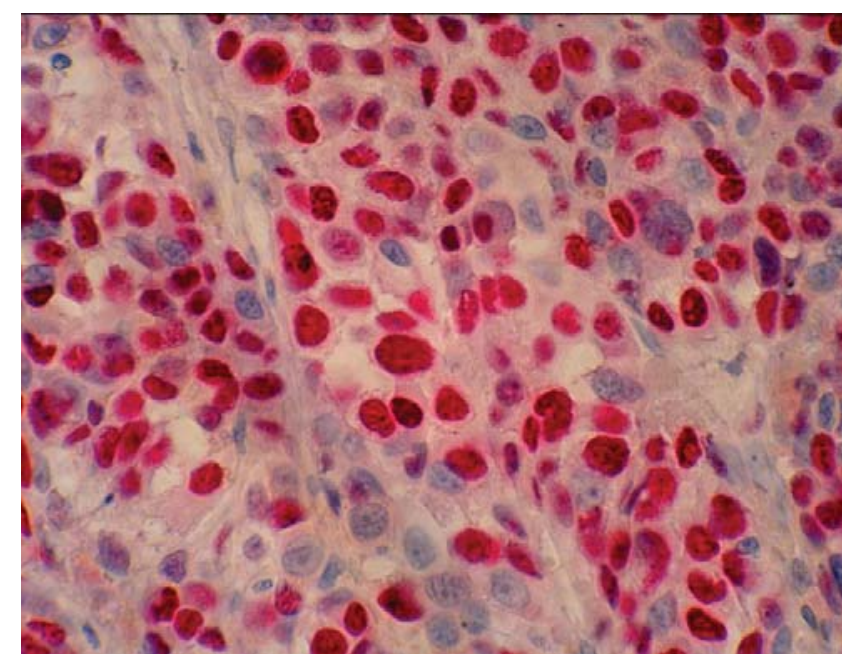

Figure 5: Expression of p53 in tumour tissue from patient with cutaneous melanoma (own Results, Anti-human p53, clone D0-7, dilution 1:75, DAKO)

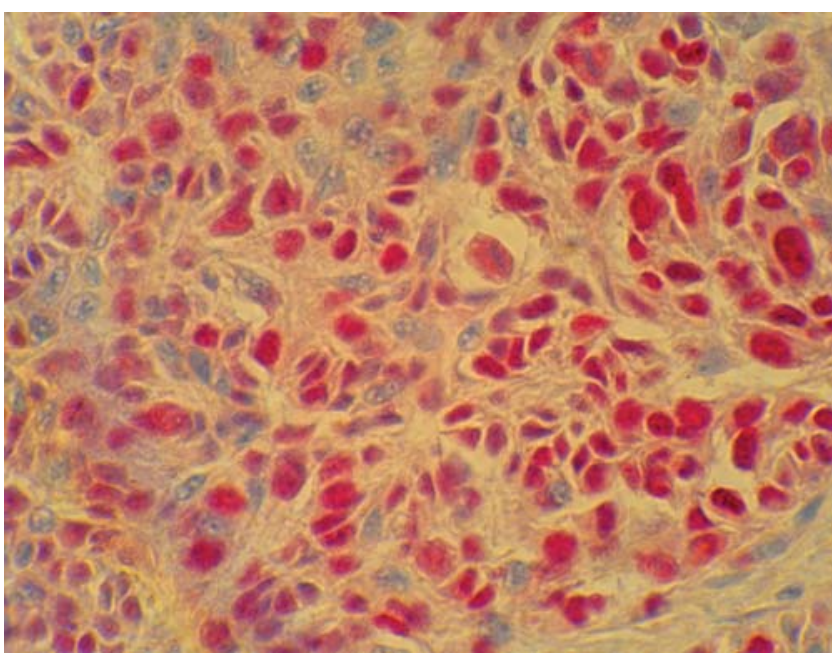

Figure 6: Expression of p21 in tumour tissue from patient with cutaneous melanoma (own Results, Anti-human p21, clone 6B6, dilution 1:75, Pharmingen)

Some members of the Bcl-2 protein family are regulated by the so called alternative splicing. A typical example is the protein Bim, which occurs in short, long and extra long forms. All forms promote apoptosis, but they also perform distinct activities and are regulated by interactions with other proteins. ${ }^{25}$ For the proapoptotic protein Bax eight splice variants have been reported, of which 6 are known to perform proapoptotic activities. ${ }^{26}$

It is also characteristic for the anti-apoptotic proteins of the Bcl-2 family to be regulated via alternative splicing. The Bcl-X gene itself is manifested in the form of several different isoforms. These isoforms may have anti- but also pro-apoptotic effect. It appears as if the alternative splicing of $\mathrm{Bcl}-2$ protein mRNAs could be regulated by different stimulus, which depends on the type of the investigated tumour and the interaction of the tumour cells with the surrounding proteins.

It is exactly because of these observations that it is difficult to establish the normal course of realization of the apoptotic pathways as well as the respective compensatory mechanisms! The direct or indirect action of a number of pro and anti-apoptotic proteins is a decision which quite often leads to life or to the "death" of cell.

Cytochrome $\mathrm{C}$ triggers the formation of the apoptosome, a complex enclosing each seven copies of the Apaf protein (Apoptosis activating factor), Cyt C and ATP. $^{27}$

Caspases are synthetized as inactive zymogens and they activate each other through different processes thus forming signal cascades.

Caspases could be devided in initiator caspases and effector caspases. ${ }^{28,29}$

Other interesting mitochondrial factors are the so called IAPs- inhibitors of apoptosis proteins. Their function is to block caspase 9 and effector caspases, which could be realized by binding to their active sites and/or by ubiquitination and targeting caspase degradation. Such factors as Smac/Diablo and HtrA2/Omi have been described to augment caspase activation by antagonizing IAP proteins. ${ }^{30,31}$

In general, the tumour tissue or tumour mass cannot be always exactly differentiated. It is unclear whether the decreased expression of a given protein is compensated with the increase expression of another or the induction of another pro- or antiapoptotic pathway. ${ }^{11}$ Or the increased expression of a new protein with a synergetic effect or an inhibitory protein "above the cascade" of the apoptotic pathways. ${ }^{2}$ Cell cycle regulation and apoptosis are dynamic processes. It would be difficult to reach conclusions regarding the prognosis for the patients on the basis of methods which reflect the state of a given protein or a molecule at a particular moment in time (Figures 3,4,5,6). New proteins are found on a monthly basis and they participate directly or not in the regulation of the mitochondrial apoptosis. And, most probably, new ones will be found in the near future.

On the other hand the interactions between the immune system and the tumour formation are of importance. ${ }^{1}$ These interactions are different in single patients and differ themselves for one and the same tumour within similar groups of patients. Another reason of importance is the unclear order of activation of the compensatory regulatory mechanisms, namely their sequence in both healthy and tumour tissue. The various tumour tissues and the same tumour tissues in different patients demonstrate often differences in the apoptotic cascades and the regulation of the cell cycle. 


\section{Modern therapeutic approaches - A New Hope?}

Suppression of apoptosis is central to the development of cancer and it is associated with resistance to many adjuvant treatments. Molecules, therefore, and pathways of apoptotic processes are targets for the development of anti-cancer treatment options. Since apoptosis is executed by intracellular proteins, molecular approaches must incorporate a method to deliver the treatment into the tumor cells. ${ }^{32}$

The examination of (TAT-Bim) shows for example that it can induce apoptosis in several cancer cell lines (T-cell lymphoma (EL4), pancreatic cancer (Panc-02), and melanoma (B16)) and whether TATBim treatment synergized with radiation. ${ }^{32}$

A mutant TAT-Bim peptide with no biologic activity (TAT-Bim-inactive) could be used as a control. ${ }^{32}$ C57/BL6 mice were challenged with syngeneic cancer cell lines and the effects of intratumoral TAT-Bim injection on tumor growth and host survival were determined. $^{32}$

It could be realized that TAT-Bim was internalized by all cancer cells within two hours.

TAT-Bim resulted in apoptosis in a dose dependent fashion in all cell lines and sublethal irradiation augmented the effects of TAT-Bim induced apoptosis. ${ }^{32}$

It seems that TAT-Bim could significantly slow the tumor growth in murine models of pancreatic cancer and melanoma. It exemplifies a strategy for cancer therapy that involves inducing apoptosis by antagonizing the endogenous anti-apoptotic "machinery".

It is as a result of such, somewhat non-standard investigations, that one realizes that the apoptotic model is still very much on a theoretical level. In vivo conditions cannot be compared always with the conditions in vitro.

The clinical importance of similar discovered significant correlations is questionable or - it may be said - that its clinical importance at present is unclear!

The differentiated testing of singular apoptotic markers and regulators of the cell cycle (whether in vivo or in vitro conditions) gives theoretical models and hopes, the clinical application of which (at the moment) is a matter of considerable doubt.

\section{ABT -737 against Bcl-2 and Bcl-XL and Bcl-W ?}

Since apoptosis is impaired in malignant cells overexpressing prosurvival $\mathrm{Bcl}-2$ proteins, drugs mimicking their natural antagonists, $\mathrm{BH} 3$-only proteins, might probably overcome chemoresistance. ${ }^{33}$

The small molecule ABT- 737 triggered Bax/Bakmediated apoptosis. Despite its high affinity for Bcl-2, $\mathrm{Bcl}-\mathrm{x}(\mathrm{L})$, and Bcl-w, many cell types proved refractory to $\mathrm{ABT}-737 .{ }^{33}$

The results from a number of investigations, however, are unsatisfactory. It appears as if the sensitivity of the molecule to block certain antiapoptotic representatives of the Bcl-2 family is not ubiquitous or problem-free but rather depends on the expression of a number of other factors, among which is Mcl-1.

\section{TW-37 against Bcl-2?}

The administration of TW-37, as a potent Bcl-2 and Mcl-1 inhibitor, to standard chemotherapy may prove an effective strategy in the treatment of B-cell lymphoma and other carcinomas. ${ }^{34,35}$

TW -37 seens to be a new class of potent smallmolecule inhibitor acting on Bcl-2. One such lead compound is the benzenesulfonyl derivative TW-37, which was designed to target the $\mathrm{BH} 3$-binding groove in Bcl-2 where proapoptotic Bcl-2 proteins, such as Bak, Bax, Bid, and Bim bind. However, the precise role and the molecular mechanism of action of TW-37 have not been fully elucidated. ${ }^{36}$ In some studies was found that TW-37 induces cell growth inhibition and S-phase cell cycle arrest, with regulation of several important cell cycle-related genes like $p 27, p 57$, E2F1, cdc25A, CDK4, cyclin A, cyclin D1, and cyclin E. The cell growth inhibition was accompanied by increased apoptosis with concomitant attenuation of Notch-1, Jagged-1, and its downstream genes such as Hes-1 in vitro and in vivo. ${ }^{36}$

Pre-exposure of lymphoma cells to TW-37 significantly enhanced the killing effect of (CHOP) regimen. The maximum tolerated dose of TW-37 in severe combined immunodeficient (SCID) mice was 40 $\mathrm{mg} / \mathrm{kg}$ for three i.v. injections when given alone and $20 \mathrm{mg} / \mathrm{kg}$, x3 when given in combination with CHOP. Using WSU-DLCL 2 -SCID mouse xenograft model, the addition of TW- 37 to CHOP resulted in more complete tumor inhibition compared with either CHOP or TW-37 alone.

As adjuvant or a supplementary option, these molecules effect or reduce the tumour mass. Alas, notions like "complete tumor inhibition" sound only too promising, and in particular in the case of the "mouse xenograft model" but not always reliable.

It is not clear whether in the near or more distant future the above-mentioned molecules will play an important role in clinical practices or in dermatooncology or will remain an inseparable part of the so-called "well sustained" theoretical model?

Very often, the treating physician is confronted by the following dilemma:

1) Why is it that in literature similar and analogical research is being performed on similar groups of patients who, however, give contradictory results?

The reason may be found in the complexity of the tumours and their progression as well as the lack of an opportunity to standardize the available infor- 
mation and to use it for each and every patient.

It may also be found in the restricted methods, which come to characterize only a part of the processes of proliferation and programmed cell death but not the interaction with the immune system for example.

The teams of researchers, specialized in the detailed simultaneous analysis of the above-quoted units are also very restricted.

\section{SEQUENCE OF REPARATION MECHANISMS BASED ON CLINICAL PATHOLOGICAL OBSERVATION}

Utilizing the melanocitic lesion as a simplified behavioral model in the direction toward an initial atypical cell one may draw important conclusions regarding the sequence of activation of the reparational systems of the organism.

In the daily excision of dysplastic melanocytic lesions - the so called melanocytic naevi - the pathologist seldom discovers T-cell perilesional infiltrates around the lesions. This brings one to the idea that initially, the atypical character of the cells may be induced during the stage of disturbance within the frame work of the proliferation and the apoptosis of the cells. Evidence of this is no doubt the lack of immune response and also the increased or decreased expression of a given protein (apoptotic, antiapoptotic) in the histological preparation. It is this lack which explains the sequence of activation of the processes of neutralization of the tumour cells in the lesional tissue. At least during the initial stages this sequence remains constant. "Guilty" for the elimination of the cells are probably the disturbances in the cell cycle regulation and the impossibility to initiate a programmed cell death, or the so-called apoptosis.

It is not clear if in such cases the decreased expression of a given protein from the Bcl-2 family (with a pro or anti-apoptotic action) and/or regulator of the cell cycle or the expression of a mutation product with increased or decreased concentration in the tumour tissue could be seen as reason or a final result? At present state this remains unclear. ${ }^{11}$

The interpretation of such data derived from large groups of patients is very difficult and not always possible. Another opened question is whether the histopathological evaluation as a whole (in a single moment) may, in general, be related to the cumulative live span in patients?

Global literary data indicate that the difference in the expressions of given proteins in the tissue established by experienced pathologists varies between 1 - $30 \%$. The question is: can we speak of exact cumulative live span and clinical importance of the statistical significance in the range of $2-3-5$ and even $10 \%$ in certain patient groups?
The massive perilesional T-cell infiltrates in melanocytic lesions are observed more often in patients with well expressed and atypical character of the melanocytes, with average thick melanomas and during the advanced stages of the melanoma.

In some rare cases it is possible that in certain or single melanocytic lesions (non-malignant) is totaly eliminated from the T-cell immune response: a fact which is conformed by a number of photographs of patients in whom subsequently the lesion could be observed, completely disappears or undergo regress. It would, doubtless be interesting if the T-cell subpopulations in such patients could be immunophenotyped - in the blood and in the lesional tissue! Observing such patients could supply us with valuable information regarding the role of the T-cell immunity for the elimination of the dysplastic melanocytic lesions and melanomas. Unfortunately it is impossible to eliminate half of the melanocytic lesion in the patient observing at the same time, whether the other half will regress or not. In the case of eliminating the whole melanocytic lesion it still remains unknown whether the established T-cell infiltrates could be able to neutralize the whole dysplastic cells, whether in a closer or a more far-off plan?

It is completely different issue, on the other hand, that in different patients the role of the programmed cell death, the cell regulation and the immunological response are far from being equivalent. ${ }^{1}$

It is very probable that within the framework of the evolution of the melanocytic lesions of primary importance for the development of a dysplastic or neoplastic lesion are the processes of a disturbed or non-regulated cell proliferation and programmed cell death. Quite often, the physician is up against the question: why we cannot find perilesional infiltrates around the dysplastic or atypical naevi during the early stages? The answer is still unclear although it serves as evidence that the local form of the tumour escape in melanocytic lesions is accompanied, initially, by disturbances effecting the cell cycle and the apoptosis. It is for this reason that considerable effort is being placed in this particular direction with the task of developing certain strategies which could be able specifically to eliminate the tumour or the neoplastic cells. Given impossibility to eliminate the neoplastic cells, at a later stage of the development the T-cell immunity is being activated. ${ }^{1}$ It has the task of eliminating an already created "tumour nest". Unfortunately within the framework of the evolution of the melanoma lesions, quite often this proves to be impossible or difficult.

Via the simultaneous definition of 10 or more proteins in the tumour tissue it is possible to an 
extent, to make an attempt to define the behaviour of tumour cells for a given patient and for a given moment but no general conclusions may be drawn for the cumulative survival as a whole (Figures $3,4,5,6){ }^{11,15}$ The availability of a greater number of patients in the investigated groups could lead to a more clearly expressed or significant dependence between certain parameters and the predictions for the separate patients. ${ }^{11,15}$

But should we consider this to be the decisive step? Is this the true or necessary information?

The melanoma has several histopathological variants which demonstrate differences in their clinical behaviour. In spote of the great number of groups of scientists in the World working on the subject of the evolution of tumour cells (in view of the need to find a certain behavioural stereotype) the results obtained so far are disheartening. The statistical importance, although significant, is not always equivalent to the notion of clinical significance! The results from a number of investigations quoted in the available literature must be seen not only from the point of view of science but also from the point of view of the practising physician.

Over $70 \%$ of the performed researches described in world literature are based on theoretical models and they cannot find a wide clinical application, in spite of the fact that the results from the investigations reveal a strictly defined (significant) interrelation. ${ }^{11,15}$

It is an opened question whether these are the dependancies which we want to see or the dependencies we cannot explain. And for which we might here and there - find some kind of an answer.

\section{Connections between the different forms of Tumour Escape?}

The connection between the forms of tumour escape in the different tumours may be subjected to a standardization within the frame work of the cancer genesis. The different tumours show a varying repertoir of mechanisms with the help of which they are able to overcome attacks of the immune system on the one hand and on the other the repair systems which include the activation of the apoptosis and the regulation of the "Cell Cycle Engine".

According to other authors, the reduced apoptosis in the tumour issue is accompanied by increased apoptosis of the tumour-like infiltrating mononuclear cells, and this indirectly helps the uncontrolled proliferation. ${ }^{37}$ The immune system is practically inactivated. ${ }^{37}$

An interesting example of exogenous form of tumour escape and its link with the processes of the apoptosis may be the autocrinic secretion of Fas L, which protects the tumour cells from the Fas-mediated apoptosis (mediated by the cytotoxic lymphocy- tes)..$^{38,39}$ In the cases of melanomas of the vascular coat of the eye, the tumour cells exhibit Fas-receptor, but they are insensitive not only with respect to the T-cell mediated apoptosis, but also to the apoptosis mediated by the Fas-specific antibodies with agony provoking effect.

The melanomas of the uvea become sensitive to the Fas-mediated apoptosis only after a treatment by metalloproteatic inhibitors. In this way, the autocrinic secretion of the Fas-L protects the tumour cells from the cytotoxic lymphocytes and may, with a great deal of justification, be analyzed as a form of a tumour escape of exogenous nature, which does not directly affect the tumour cells.

The connection between the extrinsic apoptotic pathway and the exogenic form of the tumour escape is very obvious. The interpretation of apoptotic pathways is being very complex and difficult.

\section{KIR- and Lectin-Like Receptors and Tumour Escape.}

Killer cell immunoglobulin like receptors or KIR- receptors are located in the plasmatic membrane of the NK cells and they participate in the detection and elimination of tumour cells. The KIR-genes belong to the gene superfamily located in the 19 (19q13.4) chromosome. ${ }^{23,40,41}$ These genes are responsible for the KIR-receptors expression in the NK cells. Fourteen different KIR-receptors have been identified in human body. Eight of them possess inhibiting and six of them activating, or ITAM effect. The inhibiting receptors possess a long cytoplasmic part containing ITIM fragments. ${ }^{39-41}$ The KIR-family receptors possess both activating and blocking effect .

Another type of receptor molecules which have an impact on the function of the NK cells and are located on their surface, are the C-type-Lectin-LikeReceptors, belonging to NKC (Natural Killer Gene Complex). ${ }^{2,23,39}$ By analogy with the KIR receptors, they also possess both activating and inhibiting function in the transmission of the respective signals. Five types of Lectin-Like-Receptors have been discovered in the human body, expressed as hetero- or homodimers. It is considered that these receptors also play probably a key role in the tumour escape.,

The presence of immune-receptor thyrously based inhibiting sector (ITIMs) in the area of the cytoplasma is characteristic for the structure of the KIR- and Lectin-Like- Receptors transmitting an inhibiting signal.

The activating receptors of both groups structurally differ from the inhibiting receptors. Latter contain amino-acidic sector located in the transmembranous area of the cell, additionally allowing the association of the adaptor molecules, such DAP-10 and DAP12. Adaptor molecules possess immuno-receptorial- 
based- activating-area (ITAMs) which is responsible of the transmission of activating signal after the association with the respective ligand. Most of the inhibiting receptors of the Natural Killer Gene Complex have affinity to HLA-I molecules, while the inhibiting NKR identify fragments analogous to the HLA-I molecules, such as HLA-G for instance. ${ }^{23,39,41}$

It is considered that the tumour escape is generated by direct or indirect changes affecting the KIRand/or Lecitin-Like-Receptors, and also by the their interaction with the representatives of the HLAsystem. ${ }^{23,39,41}$ The association of HLA-I with the inhibiting KIR-receptors of the NK cells leads to the generation of an inhibiting signal to the cells of the immune system, and this way, this association protects the normal cells from immune reaction.

Some malignant cells have the property to lead to a low expression of the HLA-I system and, this way to indirectly avoid the transmission of an activating signal to the NK cells and this, in consequence, should lead to their further elimination.

Another possibility of tumour escape is the association of the NK cells with proteins, analogous to the HLA molecule (HLA-G, for instance). The HLA$\mathrm{G}$ isoform is, structurally, a typic HLA-I molecule, containing alpha $-1,-2$ and -3 extracellular domains, which are incovalently associated with beta-2-microglobulin. ${ }^{42,43}$ The HLA-G1-isoform has been discovered in the form of membranously associated protein, located on the cellular surface. The HLA-G protein is a key mediator in the development of immune tolerance not only in the case of tumours, but also in a number of immunologic diseases. ${ }^{44.48}$

The high regulation of the inhibiting HLA-G molecule in some tumours (glioma and kidney carcinoma) confirms its essential importance in the processes of malignant transformation. ${ }^{45-46}$

The expression of the HLA-G molecule in patients having melanoma metastasis underlies the tumour progression because of the impossibility of a direct activation of the NK-cells.

\section{CONCLUSIONS}

1) The establishment of rigorously defined dogmas of behaviour of tumour cells in every kind of tumour, as well as in each individual results is problematic and not always possible.

2) The notion of "tumour escape" cannot be subjected to standardization within the framework of the processes which relate to the genesis of cancer. Tumour escape is a variable quantity; it is not constant. This is valid not only for the different tumours but also for similar or same tumours in different patients.

3) Utilizing the evolution of the melanocytic lesion in the direction of atypical melanocytic lesion or MM one may draw the conclusion that the two forms of tumour escape demonstrate - to an extent - a kind of sequence: the endogenic form of tumour escape effects the dysregulation of the regulators of the cell cycle and the apoptosis in the tumour tissue. The exogenic form of the tumour escape probably focuses in one or another way on the inactivation of the immune system. Inspite of the fact that between the two forms (exogenic and endogenic) there is a connection within the framework of the so-called extrinsic apoptotic pathway it is, therefore, possible that the endogenic form comes before the exogenic. This observation is probably of great importance for defining the sequence of the anti-tumour therapy and the development of new and reliable therapeutic concepts.

4) In other tumours, the deactivation of the immune system or the so-called exogenic form of tumour escape appears to be the leading factor during the very early stages of the cancer genesis. This serves to additionally complicate therapeutic concepts and visually illustrates that there is no such thing as standard behaviour of tumour cells.

5) The apoptosis, the cell prolifertation and the immune system are connected between each other in a complex network. ${ }^{1,11}$ In different individuals this network shows considerable differences, not only in the activation of the reparation systems but also in the initiation of certain compensatory mechanisms the major goal of which is the elimination of the tumour cells and the maintenance of a healthy genom. This leads to the creation of different medical hypotheses which partially turn out to be true but valid only for a given patient. This is a visual explanation of why the results obtained by the clinicians and researchers, related to patients in one and the same stage of the illness, are fundamentally different.

6) A separated testing of singular apoptotic markers and regulators of the cell cycle (whether under conditions in vitro or in vivo) gives theoretical models and theoretical hopes the clinical applicability of which remains an opened question. ${ }^{11,15}$ It is logical (to a certain degree) for cell cultures (as well as eliminated human tumour tissue also) to react in a similar way (increate apoptosis) after the application of a number of specific other components.

Conditions in the living organisms cannot be always reproduced in laboratory conditions. Outside of the human organism, tumour tissue cannot utilize its protective and attacking mechanisms, or - putted in other terms - it changes its behaviour. The expression of the proteins in the tumor tissue also changes immediately after the termination of blood flow to the tumor mass (particulary in well blood supplied tumors). This probably changes not only the secretion 
sample of certain proteins located along the tumor surface but also the secretion of different humoral factors factors in the blood circulation.

7) Via the investigations, a number of researchers have demonstrated statistically substantiated results between the disturbed processes of cell proliferation and the programmed cell death relative to the cumulative life duration of certain groups of patients.

One should not forget that the information which relates to cell cycle and the apoptosis are still just a theoretical model and do not find a wide application in the clinical practice.

The decrease in tumour mass and the increase in the sensibility of cancer cells after a therapy with anti-sence oligonucleotides in melanomas, for example, should not be viewed as some kind of a "great success". Patient forecasts in general remain reatively constant or constantly bad to unsatisfactory. Doubtless the definition of pro and anti-apoptotic proteins and the regulators of the cell cycle in the tissue is important. ${ }^{11}$ It gives important information but this information cannot be moulded into a standard for each patient or for groups of patients without a number of additional investigations.

8) Clear distinctions must be made between the notions of statistical significance and clinical importance! Not always does statistical significance mean and not always it is accompanied by clinical importance!

9) Statistical significance not always is and should be an indicator for clinical behaviour and clinical decisions, related to the fate of the patient!

\section{ACKNOWLEDGEMENTS}

No sources of funding were used to assist in the preparation of this review. The author has no conflicts of interest that are directly relevant to the content of this review. 


\section{REFERENCES}

1. Tchernev G. Apoptotic pathways, Cell Cycle Regulation and Cancer Progression. Turkiye Klinikleri J Med Sci. 2009;29:952-8.

2. Malmberg KJ, Ljunggren HG. Escape from immuneand nonimmune-mediated tumor surveillance. Semin Cancer Biol. 2006;16:16-31.

3. Tchernev G, Orfanos CE. Antigen mimicry, epitope spreading and the pathogenesis of pemphigus. Tissue Antigens. 2006;68:280-6.

4. Tchernev G, Dagatti MS, Apostolova M, Trebing D, Göring HD. Molecular Mimicry, Lichen ruber planus und die Dermatologic Masquerade. Derm Hamburg. 2009;3:226-35.

5. Igney FH, Krammer PH. Tumour counterattack: fact or fiction? Cancer Immunol Immunother. 2005;54:1127-36.

6. Khong HT, Restifo NP. Natural selection of tumour variants in the generation of "_umour escape“ phenotypes. Nat Immunol. 2002;3:999-1005.

7. Ghebeh H, Mohammed S, Al-Omair A, Qattan A, Lehe C, Al-Qudaihi G, et al. The B7-H1(PD-L1) lymphocyteinhibitory molecule is expressed in breast cancer patients with infiltrating ductal carcinoma: correlation with important high-risk prognostic factors. Neoplasia. 2006;8:190-8.

8. Hallermalm K, De Geer A, Kiessling R, Levitsky V, Levitskaya Y. Autocrine secretion of FAS ligand shields tumor cells from Fas-mediated killing by cytotoxic lymphocytes. Cancer Res. 2004;64:6775-82.

9. Abrams SI. Positive and negative consequences of Fas/Fas ligand interactions in the antitumour response. Front Biosci. 2005;10:809-21.

10. Funk J, Kind P. Zellzykluskontrolle, genetische Instabilität und Krebs. Hautarzt. 1997;48: 157-16.

11. Tchernev G, Orfanos CE. Downregulation of cell cycle modulators p21, p27,p53, Rb and proapoptotic Bcl-2 related proteins $\mathrm{Bax}$ and $\mathrm{Bak}$ in cutaneous melanoma is associated with worse patient prognosis. J Cutan Pathol. 2007;34:247-56.

12. Mathai JP, Germain M, Marcellus RC, Shore GC. Induction and endoplasmic reticulum location of $\mathrm{BIK} / \mathrm{NBK}$ in response to apoptotic signaling by E1A and p53. Oncogene. 2002;21:2534-44.

13. Yu J, Zhang $\mathrm{L}$. The transcriptional targets of $\mathrm{p} 53$ in apoptosis control. Biochem. Biophys Res Commun. 2005;331:851-8.

14. Schuler M, Green DR. Transcription, apoptosis and p53: catch-22. Trends Genet. 2005;21:182-7.

15. Fecker LF, Geilen CC, Tchernev G, Trefzer U, Assaf C, Kurbanov BM, et al. Loss of proapoptotic Bcl-2 Related Multidomain Proteins in Primary Melanomas Is Associated with Poor Prognosis. J Invest Dermatol. 2006;126:1366-71.

16. Cao S, Chang KH, Luthra R, Liu J. Frameshift Mutations in the Bax Gene Are not involved in Development of Ovarian Endometroid Carcinoma. Mod Pathol. 2003; 16:1048-52.

17. Finucane DM, Bossy-Wetzel E, Waterhouse NJ, Cotter TG, Green DR. Bax-induced caspase activation and apoptosis via cytochrome c release from mitochondria is inhibitable by Bcl-xL. J Biol Chem. 1999;274:2225-33.

18. Van LA, Van KS, Lippens S, Declercq W, Vandenabeele P, Janssens S, et al. Activation of p38 MAPK is required for Bax translocation to mitochondria, cytochrome $\mathrm{c}$ release and apoptosis induced by UVB irradiation in human keratinocytes. FASEB J. 2004;18:1946-8.

19. Zheng Y, Yamaguchi H, Tian $C$, Lee MW, Tang H, Wang $\mathrm{HG}$, et al. Arsenic trioxide $(\operatorname{As}(2) \mathrm{O}(3))$ induces apoptosis through activation of Bax in hematopoietic cells. Oncogene. 2005;24:3339-47.

20. Willis SN, Chen L, Dewson G, Wei A, Naik E, Fletcher JI, et al. Proapoptotic Bak is sequestered by Mcl-1 and Bcl$\mathrm{xL}$, but not Bcl-2, until displaced by $\mathrm{BH} 3$-only proteins. Genes Dev. 2005;19:1294-1305.

21. Daniel P. Dissecting the pathways to death. Leukemia. 2000;14: 2035-44.

22. Daniel P, Wieder T, Sturm I, Schulze-Osthoff K. The kiss of death: promises and failures of death receptors and ligands in cancer therapy. Leukemia. 2001;15: 1022-32.

23. Lanier L, Phillips J. Inhibitory MHC class I receptors on NK cells and T cells. Immunol Today. 1996;17:86.

24. Valiante NM, Uhrberg M, Schilling HG, LienertWeidenbach K, Arnett KL, et al. Functionally and structurally distinct NK cell receptor repertoires in the peripheral blood of two human donors. Immunity. 1997; 7:739-51.

25. Ewings KE, Wiggins CM, Cook SJ. Bim and the prosurvival bcl-2 proteins - Opposites attract, ERK repels. Cell Cycle. 2007;6:2236-40.

26. Akgul C, Moulding DA, Edwards SW. Alternative splicing of Bcl-2-related genes: functional consequences and potential therapeutic applications. Cell Mol Life Sci. 2004;61:2189-99.

27. Saikumar P, Mikhailova M, Pandeswara SL. Regulation of caspase-9 activity by differential binding to the apoptosome complex. Front Biosci. 2007;12:3343-54.

28. Los M, Stroh C, Janicke RU, Engels IH, Schulze-Osthoff K. Caspases: more than just killers? Trends Immunol. 2001;22:31-4.

29. Degterev A, Boyce M, Yuan J. A decade of caspases. Oncogene. 2003;22:8543-67.

30. Shiozaki EN, Shi YG. Caspases, IAPs and Smac/DIABLO: mechanisms from structural biology. Trends Biochem Sci. 2004;29:486-94.

31. Walle LV, Lamkanfi M, Vandenabeele $P$. The mitochondrial serine protease HtrA2/Omi: an overview. Cell Death Differ. 2008; 15:453-60.

32. Kashiwagi H, McDunn JE, Goedegebuure PS, Gaffney MC, Chang K, Trinkaus K, et al. TAT-Bim Induces Extensive Apoptosis in Cancer Cells. Ann Surg Oncol. 2007;14:1763-71.

33. van Delft MF, Wei AH, Mason KD, Vandenberg CJ, Chen L, Czabotar PE, et al. The BH3 mimetic ABT-737 targets selective $\mathrm{Bcl}-2$ proteins and efficiently induces apoptosis via Bak/Bax if Mcl-1 is neutralized. Cancer Cell. 2006;10:389-99.

34. Azmi AS, Mohammad RM. Non-peptidic small molecule 
inhibitors against Bcl-2 for cancer therapy. J Cell Physiol. 2009;218:13-21.

35. Mohammad RM, Goustin AS, Aboukameel A, Chen B, Banerjee S, Wang G, et al. Preclinical studies of TW-37, a new nonpeptidic small-molecule inhibitor of Bcl-2, in diffuse large cell lymphoma xenograft model reveal drug action on both Bcl-2 and Mcl-1. Clin Cancer Res. 2007; 13:2226-35.

36. Wang Z, Azmi AS, Ahmad A, Banerjee S, Wang S, Sarkar FH, et al. TW-37, a small-molecule inhibitor of Bcl-2, inhibits cell growth and induces apoptosis in pancreatic cancer: involvement of Notch-1 signaling pathway. Cancer Res. 2009;69:2757-65. Epub 2009 Mar 24.

37. Chen GG, Lee JF, Chan UP, Xu H, Ip PC, Lau WY. Increased apoptosis in infiltrating mononuclear cells of colorectal cancer: a mechanism for tumour escape. Arch Pathol Lab. 2002;126:686-91.

38. Ibrahim R, Frederickson H, Parr A, Ward Y, Moncur J, Khleif SN. Expression of Fas L in squamous cell carcinomas of the cervix and cervical intraepithelial neoplasia and its role in tumour escape mechanism. Cancer. 2006;106:1065-77.

39. Chouaib S, Thiery J, Gati A, Guerra N, El Behi M, Dorothée G, et al. Tumour escape from killing: role of killer inhibitory receptors and acquisition of tumour resistance to cell death. Tissue Antigens. 2002;60:273-81.

40. Paweleg G. Tumour escape: antitumour effectors too much of a good thing? Cancer Immunol Immunother. 2004;53:262-74.

41. Urosevic M, Trojan A, Dummer R. HLA-G and its KIR ligands in cancer- another enigma yet to be solved ? J Pathol. 2000;196:252-3.

42. Carosella ED, Rouas-Freiss N, Paul P, Dausset J. HLA-G: a tolerance molecule from the major histocompatibility complex. Immunol Today. 1999;20:60.

43. Hviid TVF. HLA-G in human reproduction: aspects of genetics, function and pregnancy complications. Hum Reprod Update. 2006;12:209-32.
44. Rouas-Freiss N, Marchal R, Kirszenbaum M, Dausset J, Carosell ED. The a1 domain of HLA-G1 and HLA-G2 inhibits cytotoxicity induced by natural killer cells: Is HLA-G the public ligand for natural killer cell inhibitory receptors? Proc Natl Acad Sci USA. 1997;94:5249.

45. Wiendl H, Mitsdoerffer M, Hofmeister V, Wischhusen A, Meyermann R, et al. A Functional Role of HLA-G Expression in Human Gliomas: An Alternative Strategy of Immune Escape. J Immunol. 2002;168:4772-4780.

46. Bukur J, Rebmann V, Grosse-Wilde H, Luboldt H, Ruebben H, Drexler I, et al. Functional role of human leukocyte antigen-G up-regulation in renal cell carcinoma.. Cancer Res. 2003;63:4107-11.

47. Wiendl H, Feger U, Mittelbronn M, Jack C, Schreiner, et al. Expression of the immune-tolerogenic major histocompatibility molecule HLA-G in multiple sclerosis: implications for CNS immunity. Brain. 2005; 128:2689-2704.

48. Barrier BF, Kendall BS, Ryan CE, Sharpe-Timms KL. HLA-G is expressed by the glandular epithelium of peritoneal endometriosis but not in eutopic endometrium. Hum Reprod Update. 2006;21:864-9.

\author{
ENDEREÇO PARA CORRESPONDÊNCIA / MAILING ADDRESS: \\ Georgi Tchernev. \\ MVZ Kirchbeim GmbH, Department of \\ Dermatology, Venereology and Dermatologic \\ Surgery, Steingaustraße 13, 73230 Kirchbeim \\ unter Teck, Germany \\ Tel./Fax: 004970219300220004970219300221 \\ Private GSM 00491745814312 \\ Email: georgi_tchernev@yaboo.de
}

Como citar este artigo/How to cite this article: Tchernev G, Nenoff P. Dissecting the pathways of tumour escape: "a question of life and death?". An Bras Dermatol. 2010;85(2):248-59. 